\title{
Recognition and incidence of intrapulmonary lymph nodes
}

\author{
DAVIDH.TRAPNELL \\ From the Department of Diagnostic Radiology, St. Bartholomew's Hospital, London ${ }^{1}$
}

Lymph nodes are normally found in man in the mediastinum and around the main bronchi at the hilum of the lung. A few such nodes, which have confusingly been called intrapulmonary (Piéry and Jacques, 1906 ; Johnston, Davies, and Davies, 1958), may also be present alongside lobar bronchi as far into the lung as the third or fourth branching of the bronchi. Aggregations of lymphocytes are common at the bifurcations of bronchi and beneath the pleura, as Miller (1911) clearly showed. However, definite nodes with a capsule and lymphoid follicles may be found in some individuals far out in the lung and even close to the pleura. These are truly intrapulmonary and must be distinguished from those near the hilum of the lung or in the mediastinum, which may conveniently be grouped together as tracheo-bronchial lymph nodes.

According to Heller (1895), the first to describe subpleural lymph nodes was Meinel (1869), whose work was soon followed by that of Sanderson (1869) and Is (1876). Arnold (1880) showed the truly lymphoid character of these nodules and that they occurred in normal lungs. Later, Lüders (1892), Heller (1895), and Bossuet (1905) confirmed the work of the earlier authors. They showed that subpleural nodes were visible macroscopically, varying in size up to that of a lentil, being abundant in some cases and rare or absent in others.

Miller (1911, 1947) investigated the lungs of dogs and other animals as well as those of man, and failed to show definite lymph nodes in normal lungs but found in each instance small masses of lymphoid tissue. Elsewhere in his 1911 paper he said he had found definite intrapulmonary and subpleural lymph nodes: he suggested that these occurred only in abnormal lungs and that the nodes must have developed from normal masses of lymphoid tissue. However, no evidence was given to support this. Later, in 1924 and 1947, he suggested that there was a definite increase in the

1 Present address: Westminster Hospital, London, S.W.1. amount of lymphoid tissue in the lung as age increased and that this was related to the amount $\stackrel{\vec{A}}{\overrightarrow{+}}$ of carbon particles inhaled. He reported that he $\mathrm{O}$ had rarely seen a true lymph 'follicle' in a normal lung distal to the second ventral branch of the $c$

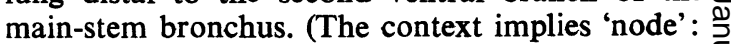
'follicles' form part of the cortex of a normal lymph node in man.) His view seems to have $₹$ influenced subsequent writers, such as Rouvière $\vec{\varphi}$ (1932), Policard (1938), and von Hayek (1960), who gave the presence of intrapulmonary lymph nodes little or no attention. Rouvière (1932) and von Hayek (1960) referred to the previous literature on the subject but indicated that they had not personally seen definite nodes in the lung. के Modern anatomical textbooks, such as those by Jones, Patterson, Mottershead, Barlow, Wilde, and음 Dobson (1949), Brash (1951, 1958), and Johnston et al. (1958), do not refer to the presence of truly intrapulmonary lymph nodes. Boyd, Clark, Hamilton, Yoffey, Zuckerman, and Appleton (1956) and Zuckerman (1961) mention the presence of lymph nodes in the lung itself but give no details.

In the radiological literature there appears to be only one case, described by Greenberg (1961), of a strictly intrapulmonary lymph node being demonstrated radiographically, its nature being revealed by subsequent operative removal and histological examination. Some other authors $\frac{7}{0}$ (Wigh and Montague, 1955; Felson, 1960) have referred to 'intrapulmonary' lymph nodes, but it $N_{\sigma}$ is clear that they were describing the bronchial nodes close to the hilum.

Because of the scanty evidence in the literature, $\omega$ it might be thought that intrapulmonary lymph nodes are extremely rare and of no particularo importance, although clinical histologists recognize their existence and do not regard them as particularly uncommon (Spencer, 1963). If such $\frac{7}{0}$ nodes are not unusual, the more general realiza- $\frac{+}{\circ}$

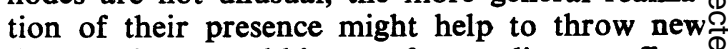
light on the natural history of some diseases affect- $\stackrel{\varnothing}{\circ}$ ing the lung. 
MATERIAL AND METHODS

The presence of intrapulmonary lymph nodes was studied in 92 lungs from 91 different patients whose ages at death ranged from 10 to 82 years. Some of the lungs were normal. In the abnormal lungs, shadows in the radiographs due to disease of the lungs may have obscured some intrapulmonary lymph nodes that would otherwise have been detected, but there was no evidence to suggest that this actually occurred.

The 92 lungs were inflated and then radiographed. Apart from a few early cases, all of these were studied using gaseous fixation (Cureton and Trapnell, 1961). Radiographs of the whole lung were made in several different planes, and any abnormal part of the lung was thus located. In a few instances it was necessary to cut the lung into slices about $1 \mathrm{~cm}$. thick and to radiograph each of these separately. In this way small lesions were found and removed for histological examination without difficulty.

In 35 of the last 46 lungs, after radiography of the inflated, but still unfixed, lung, the pleural lymphatics were injected. For this the lung was placed at a convenient height so that an area showing pleural lymphatics was uppermost and approximately horizontal, and it was then secured by wooden blocks and wet sponges. The injection material (barium sulphate (Micropaque) $80 \%$, gelatin $5 \%$, methyl hydroxybenzoate $0 \cdot 1 \%$, and water to make $100 \%$ ) was heated in a water-bath until it was hot to touch. A warm 5-ml. syringe was filled with this mixture and attached to the finest hypodermic needle available. (For the last 13 cases extra fine, 28 standard wire gauge needles were used.) The needle was then inserted into one of the larger pleural lymphatics and special care was taken not to penetrate the alveoli underneath it so that the lung remained inflated. The injection was then made by gentle manual pressure on the plunger of the syringe. Sometimes the pleural lymphatics filled easily. On other occasions the direction of the needle was opposite to that in which the valves pointed. In these circumstances there was sometimes sufficient backward leak around the needle to allow filling of the lymphatics, but at other times the contrast medium simply leaked out of the lymphatic through the needle puncture. In such cases the needle was withdrawn and another injection made in the opposite direction. It was never possible by simple inspection of a pleural lymphatic to detect with certainty the site of valves or the direction in which they pointed. When the needle had to be withdrawn and re-inserted there was often leaking through the site of the first puncture which reduced the extent of the filling subsequently obtained.

An injection was continued for as long as possible and only stopped when there was contrast medium at the hilum, leakage into the alveoli (indicated in the superficial ones by a white cloud appearing outside the lymphatics), leakage around the site of the needle puncture (or occasionally at the site of a previous puncture) or, simply, when there was no visible evidence or further extension of the injected material after about one minute during which the gentle injection pressure was maintained. The total quantity of the mixture injected never exceeded $2 \mathrm{ml}$. and was sometimes less. The duration of each injection varied from two to five minutes. In some cases rapid serial photographs were taken to record the sequence and direction of filling of the pleural lymph vessels while the injection was actually proceeding, the syringe plunger being advanced by an electrically-driven mechanical device.

An attempt was made to inject every visible lymphatic, although some of them were too small to admit even the finest neede. The very small size of some of the pleural lymphatics presented the greatest technical problem because they were much smaller than the smallest needle available. However, it was sometimes possible to outline such vessels via a communication with another larger lymphatic. Occasionally a lymphatic could be stretched with the bevel of the needle. It was necessary to use a new needle for each injection if the puncture was to be clean and the leak around the needle during the injection minimized. If the pleura became flaccid because of a leak of the formalin vapour from the lung, re-inflation was necessary before an injection was attempted. Often more time was spent in rendering the lungs really air-tight than in any other stage of the examination. Provided that the pleura was tense and the lymphatic was of a size that would admit the needle, a satisfactory puncture of the lymphatic was always made. This did not always mean, however, that a successful injection would follow because sometimes the direction of the needle was opposed to that of the lymphatic valves, as described above.

After each injection radiographs were made in several different projections to record the extent and direction of the flow of contrast medium from each injection.

\section{FINDINGS}

In only one of the 92 lungs studied did plain radiographs of the inflated lung reveal the presence of definite intrapulmonary lymph nodes (Fig. 1a, b). In this instance three nodes were present, each being approximately $0.5 \mathrm{~cm}$. in diameter.

When the pleural lymphatics were injected and there was subsequent filling of the deep lymphatics (28 cases; Trapnell, 1963) intrapulmonary nodes were outlined in five lungs $(18 \%)$. In two of these cases two intrapulmonary lymph nodes were revealed (Fig. 2). Even when the sites of these nodes had been shown by the injection material in their sinusoids, it was not possible to locate them with certainty in the radiographs made before injection of the lymphatics, presumably because there was no air around them and their radio- 

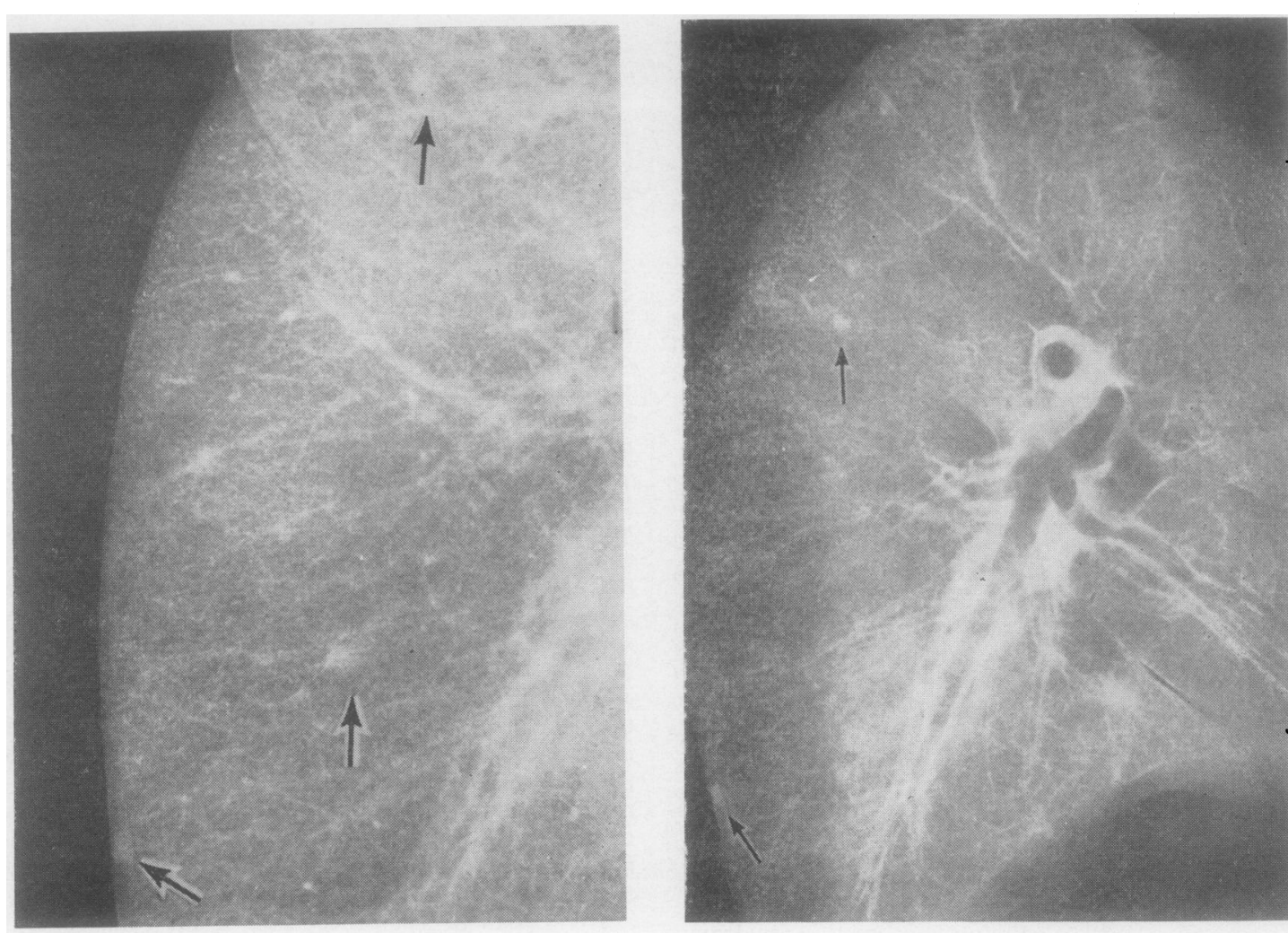

(a)

(b)

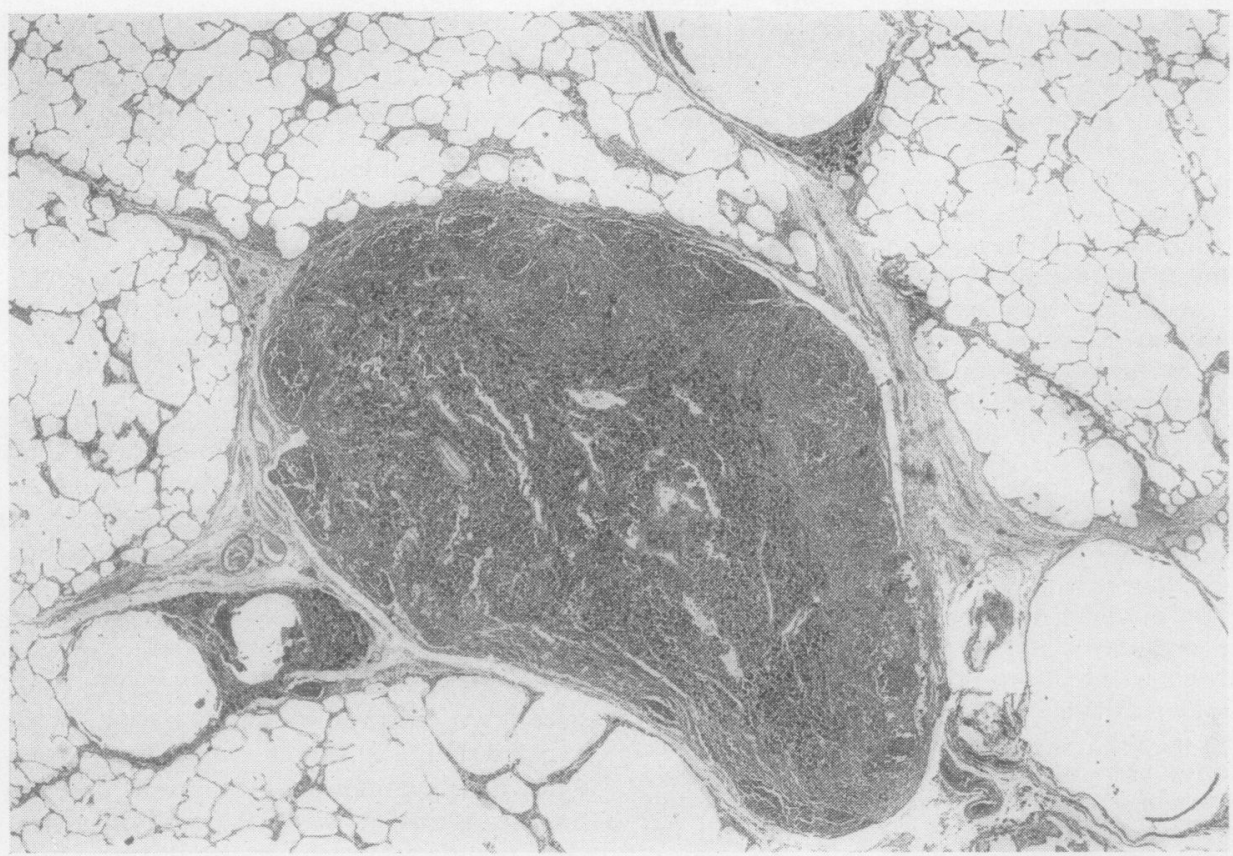

(c)

FIG. 1. (a) Part of a radiograph (original size) of a whole inflated lung showing throe abnormal opacities (arrowed), each of which proved to be due to an intrapulmonary lymph node; (b) radiograph of a slice of the same lung showing two of the opacities (arrowed); (c) photomicrograph (H. and $E ., \times 95)$ of the upper opacity shown in (b). The structure is a typical lymph node with a capsule and germinal centres. 


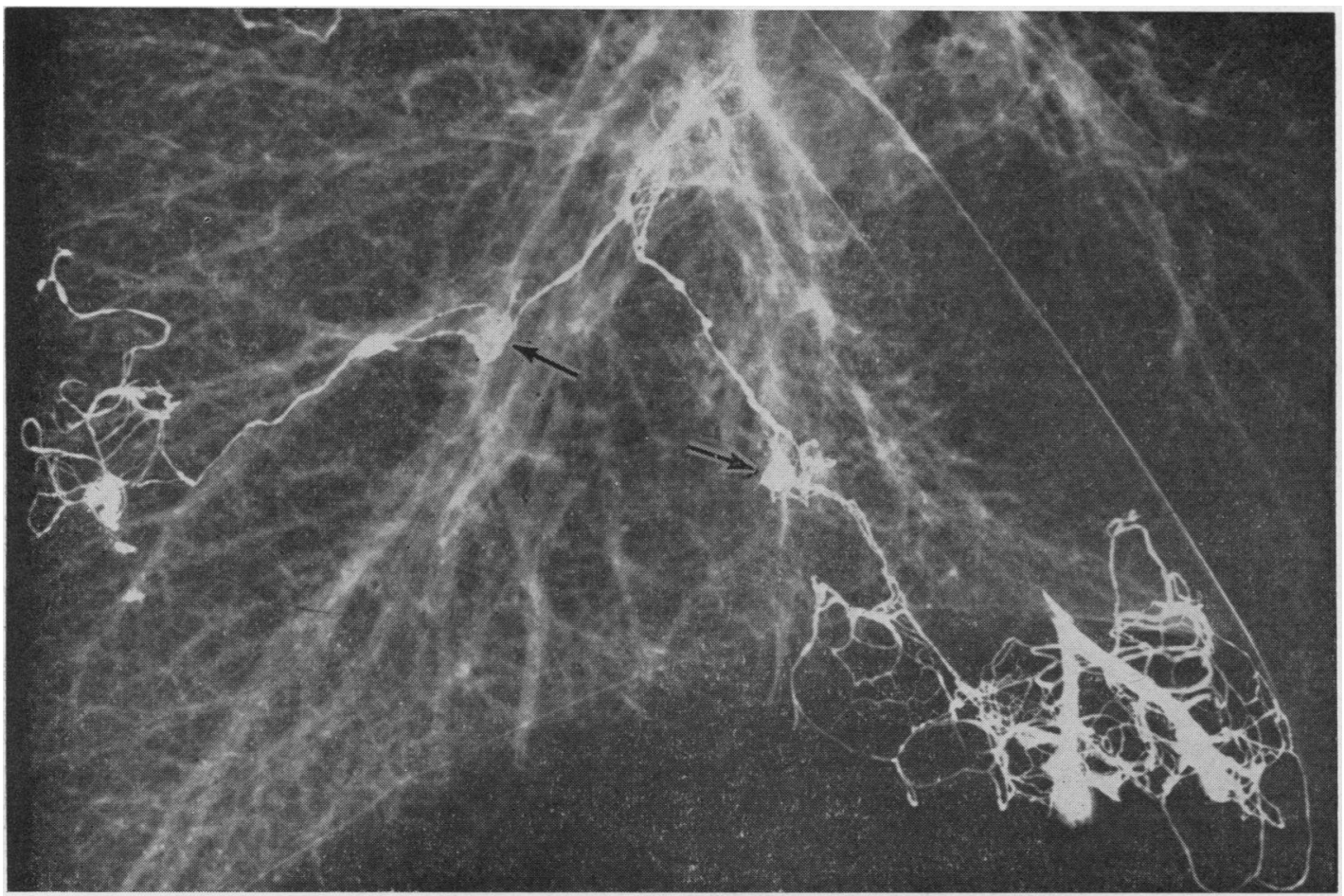

FIG. 2. Radiograph of an inflated lung after two separate injections of the pleural lymphatics of the lower lobe. Two lymph nodes have been outlined (arrowed).

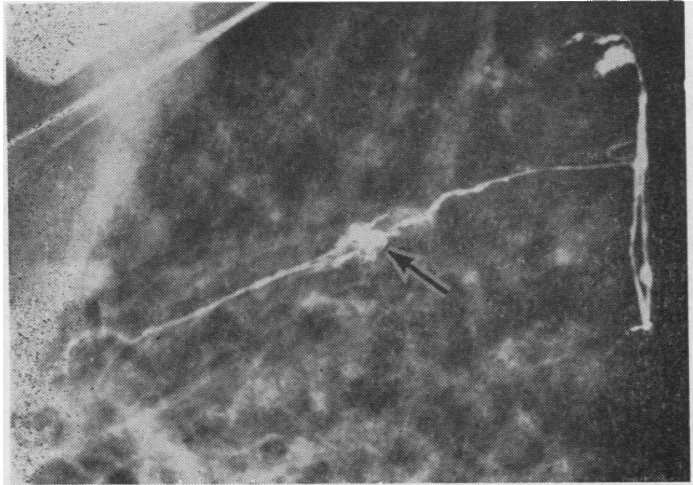

(a)

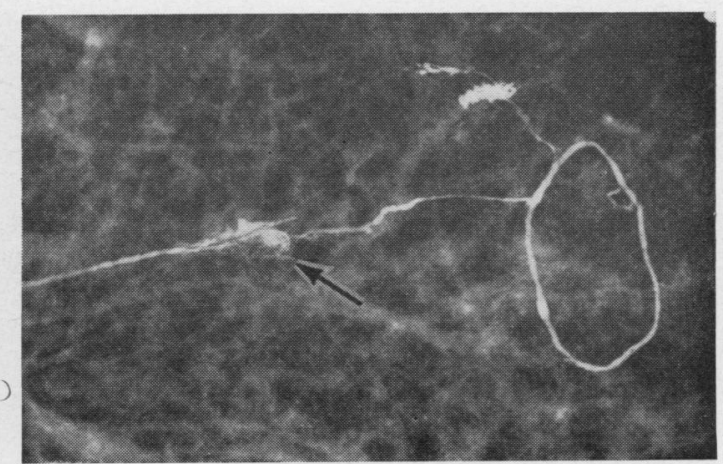

(b)

FIG. 3. (a) Radiograph (original size) of an intrapulmonary lymph node (arrowed) filled from the pleural lymphatics, here seen in profile in the right side of the figure; (b) radiograph of the same area with the specimen in a different position. The subcapsular sinus of the lymph node is well shown. 
graphic density was the same as that of the adjacent blood vessels and lung tissue. When the subcapsular sinus was outlined (Fig. $3 b$ ) and the barium mixture permeated the substance of the node, a shadow was produced that was usually dense and similar to that found when filling of the hilar nodes was obtained (Fig. 4). In one case (Fig. 5a) the radiograph showed numerous fine vessels radiating from an intrapulmonary node. Presumably many of these were filled by retrograde flow. One large vessel was shown communicating with the node near its pleural aspect. By

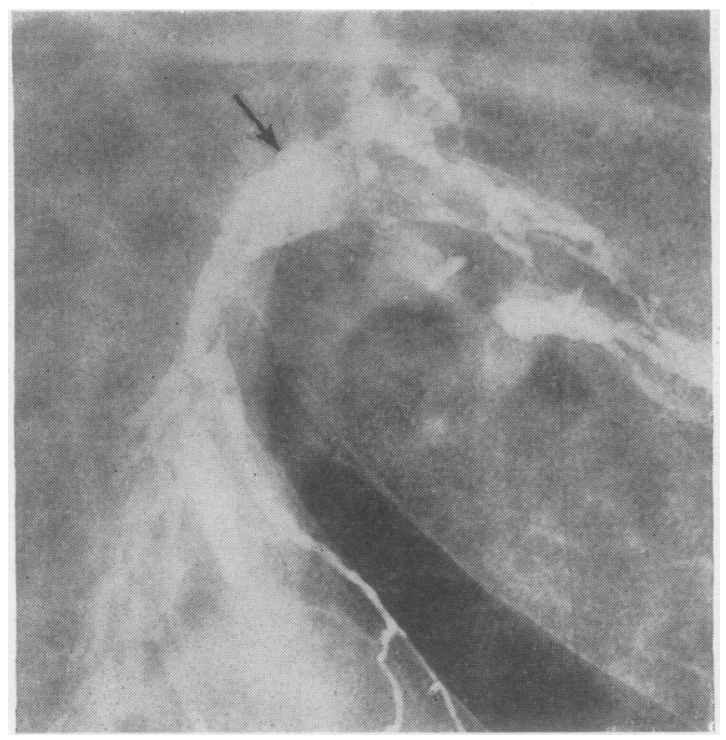

FIG. 4. Radiograph of normal hilar lymph nodes outlined with the injection medium.

analogy with lymph nodes in other parts of the body, this large vessel might be presumed to be the efferent lymphatic and the numerous fine vessels the afferent ones. If this were so, the direction of the flow in the main vessel in this case would have been towards the pleura. On the other hand, because the fine vessels were short and did not communicate with the pleural vessels, filling of the node presumably occurred from the pleura via the single large lymphatic, thus indicating either that no valve was present in it or that the competence of the valve(s) was overcome by the injection.

There was little difficulty in this series in deciding whether accumulations of lymphoid tissue should be regarded as lymph nodes or not. Those aggregations called nodes were macroscopically visible as distinct and separate structures (Fig. 1b), being at least $0.5 \mathrm{~cm}$. in one diameter and having? a capsule. Histological examination showed evi음 dence of lymphoid follicles and the presence of carbon pigment in all the nodes (Fig. 1c). Radio $\frac{\bar{s}}{6}$. graphically it was possible, in those cases where् the lymphatics had been injected, to demonstrate an subcapsular sinus in four of the five cases (Fig. 3b) In the fifth case numerous sinusoids were filledP with contrast medium, but no recognizable sub $\vec{\omega}$ capsular sinus was outlined (Fig. 5a).

In four of the cases where intrapulmonary lymph nodes were present, the lungs were radio graphically and histologically normal and there was no systemic disease that might be associated $\vec{s}$ with lymphadenopathy. Of the other two cases ${ }_{0}^{+}$ one showed radiographic and histological changes of acute bronchopneumonia, but there was no clinical or other evidence of previous lung disease the other case (Fig. 1a) showed thickening of the pleura over the lung apex and a little alveolar pulmonary oedema but no other abnormality $\vec{\circ}$ There was nothing to suggest, therefore, that anyo of the intrapulmonary lymph nodes discovered in this series was caused by a disease process or that they were in any way 'abnormal' structures.

\section{COMMENT}

In this series of 92 lungs, lymph nodes were demonstrated in the lung substance far from the hilum in six instances (7\%). In one of these casesthe lymph nodes were located by simple radio-f graphy. The others were only demonstrated when they were outlined with the barium mixture used $\vec{b}$ to inject the pleural lymphatics. If it had beenv possible to inject more of the pulmonary lymph vessels the presence of more intrapulmonary. lymph nodes might have been revealed.

Miller $(1911,1924)$ suggested that intra pulmonary lymph nodes were not present in normal lungs and that the quantity of lymphoid tissue present in lungs was proportional to thes amount of carbon inhaled during life and thus that. there was a definite increase of both in old age. All the intrapulmonary lymph nodes of this series contained carbon particles. It may be that the inhalation of large quantities of carbon, an $\tilde{w}^{\omega}$ perhaps other kinds of dust, may cause hypers trophy of lymphoid tissue in the lung ${ }^{2}$. The lung\& of the six cases studied were radiologically and histologically normal apart from the presence of a little acute alveolar pulmonary oedema in ons 1 It seems unlikely that the presence of intrapulmonary lympiñ nodes depends entirely on age ; my youngest patient of about $2 \frac{\Omega}{4}$

showed three such nodes.
2 However, I have no evidence to substantiate or disprove that the nodes are made larger or more numerous by the presence of carboro or other particles. 


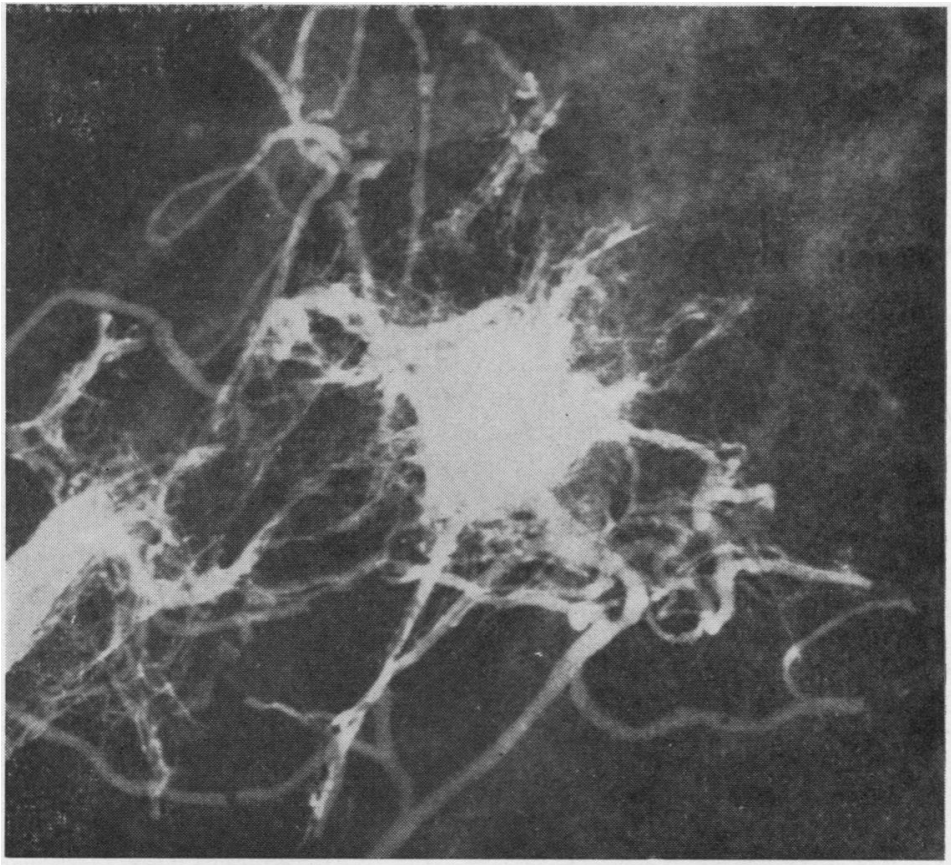

(a)

F1G. 5. (a) Radiograph (enlarged $\times 2$ ) showing a lymph node from which numerous fine lymphatics spread. No subcapsular sinus is visible; (b) photograph (enlarged $\times 6$ ) of the cut surface of the specimen showing the lymph node with black carbon and the white injection medium in it. Several small radiating lymphatics are also visible. A peribronchial network of lymph vessels is shown on the left of the photograph.

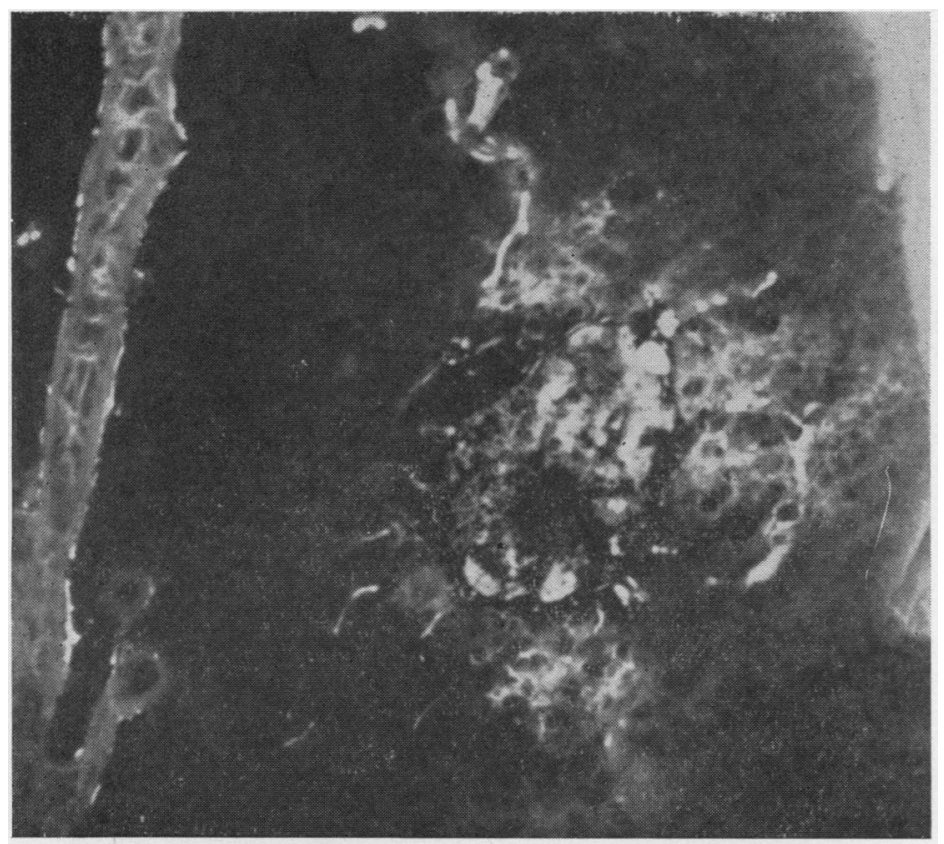

(b) 
and acute (terminal) bronchopneumonia in another.

The age of the patients in whom intrapulmonary nodes were demonstrated ranged from about 25 (exact age uncertain) to 82 (average 56) years. The patient described by Greenberg (1961) was a man aged 58 years, who had had a chronic cough and been a moderately heavy smoker for many years. Because the average age of those who die in this country is high, it may be some time before it is possible to say whether such intrapulmonary lymph nodes are more common in the older age groups or not. It is not yet clear whether the aggregations of lymphoid cells commonly present near the bifurcation of bronchi may develop into true lymph nodes or whether the intrapulmonary nodes have been present as such since childhood.

On the basis of this series it is not possible to indicate the true incidence of intrapulmonary lymph nodes. It is clear, however, that they are much more common than might be supposed from a study of the literature. There appears to be only one recorded instance where an intrapulmonary node has been recognized in a chest radiograph of a living patient (Greenberg, 1961). It is most unlikely that it will be possible to detect accurately the presence of intrapulmonary lymph nodes by radiographic methods during life, and the proof of their existence will still have to depend upon their removal at thoracotomy or necropsy. None the less, in the interests of anatomical accuracy it is important that the presence of such nodes should be appreciated. Further, this fact may help towards a fuller understanding of the development of such diseases as intrapulmonary Hodgkin's disease.

\section{SUMMARY}

In six of 92 lungs (7\%) studied by inflation and radiography, lymph nodes were found in the lung far from the hilum. Five of these cases were only found when the lymphatics were injected and the deep lymph vessels outlined (28 cases). Such nodes are not nearly so uncommon as is suggested by the literature.
I am indebted to the physicians and surgeons of St. $\overrightarrow{\overline{\vec{\omega}}}$ Bartholomew's Hospital, London, for permission too study their cases, to Dr. R. D. Teare for one of theō lungs, to the pathologists who removed the other lungs post mortem and, particularly, to Dr. R. J. R. Cureton for his help with the selection and interpreta-응 tion of the histological material. I am very grateful tow the Departments of Medical Photography at St. Bar- $\vec{\circ}$ tholomew's Hospital and Westminster Hospital for the reproductions of the radiographs, to $\mathrm{Mr}$. P. J. Crocker $\vec{\omega}$ for the photomicrographs, and to Mr. J. W. Miller foro the histological preparations.

\section{REFERENCES}

Arnold, J. (1880). Ueber das Vorkommen lymphatischen Gewebes ino den Lungen. Virchows Arch. path. Anat., 80, 315.

Bossuet, G. (1905). Nodules et ganglions lymphatiques de la surface

externe du poumon. J. Mid. Bordeaux, 35, 257 .
Boyd, J. D., Clark, W. LeGros, Hamilton, W. J., Yoffey, J. M. Zuckerman, S., and Appleton, A. B. (1956). Textbook of HumarD Anatomy, ed. W. J. Hamilton, pp. 393-394. Macmillan, London

Brash, J. C. (1951). Cunningham's Text-book of Anatomy, 9th ed Oxford University Press, London.

(1958). Cunningham's Manual of Practical Anatomy, 12th ed. Vol. 2. Oxford University Press, London.

Cureton, R. J. R., and Trapnell, D. H. (1961). Post-mortem radio graphy and gaseous fixation of the lung. Thorax, 16, 138

Felson, B. (1960). Fundamentals of Chest Roentgenologv, pp. 168-173 Saunders, Philadelphia.

Greenberg, H. B. (1961). Benign subpleural lymph node appearing as? a pulmonary 'coin' lesion. Radiolog. $77,97$. von Hayek, H. (1960). The Human Lung, trans. V. E. Krahl, pp. $298-\frac{\oslash}{314 \text {. Hafner Publishing Co., New York. }}$

Heller, A. (1895). Ueber subpleurale Lymphdrüsen. Dtsch. Arch. kling Med., 55, 141.

Is, V. (1876). Inaug. Diss. Bern, p. 14, quoted by Heller, A. (1895),

Johnston, T. B., Davies, D. V., and Davies, F. (1958). Gray's Anatomy $\vec{T}$ 32 nd ed., p. 910 . Longmans, Green, London.

Jones, F. Wood, Patterson, E. L., Mottershead, S., Barlow, T. E. 윽 Wilde, F. R., and Dobson, J. (1949). Buchanan's Manual of Anatomy, 8th ed., Baillière, Tindall and Cox, London.

Lüders, C. (1892). Inaug. Diss. Kiel, quoted by Rouvi re, H. (1932)

Meinel (1869). Inaug. Diss. Erlangen, p. 43, quoted by Heller, $A$

Miller, W. S. (1911). The distribution of lymphoid tissue in the lung Anat. Rec., 5, 99.

- (1924). The pulmonary lymphoid tissue in old age. Amer. Rev Tuberc., 9, 519. (1947). The Lung, 2nd ed., pp. 119-135. Thomas, Springfield

Piźry, M., and Jacques, A. (1906). Les adónopathies pulmonaires etude anatomique, radioscopique et clinique. Rev. Midecire, 26 ? 664.

Policard, A. (1938). Le Poumon, pp. 288-291. Masson, Paris.

Rouvière, H. (1932). Anatomie des Lymphatiques de l'Homme, p. ${ }^{189} \mathrm{O}$ Masson, Paris

Sanderson, J. B. (1869). Recent researches on tuberculosis. Edinb med. J., 15, 385.

Spencer, H. (1963). Personal communication. Trapneli, D. H. (1963). The peripheral lymphatics of the lung. Brit. $J$. Radiol, N.S., 36, 660

Wigh, R., and Montague, E. D. (1955). Evaluation of intrapulmonic

Zuckerman, S. (1961). A New System of Anatomy, p. 531. Oxford University Press, London. 